\title{
Mental toughness and its relationship to the achievement level of the weightlifters in Egypt
}

\author{
Ahmed ELEMIRI ${ }^{1}$, Ahmed ALY² \\ ${ }^{1}$ Department of Curriculum and Teaching Methods, Faculty of Sport Education Al-Mansoura University, Egypt. \\ ${ }^{2}$ Department of Sports Psychology, Faculty of Sport Education Al-Mansoura University, Egypt. \\ Address correspondence to A. Elemiri, e-mail: Gewichtheber_aboamr@yahoo.de
}

\begin{abstract}
Mental Toughness (MT) is a crucial factor for super-elite athletes "Olympians", since differences in physical and technical competences are minimal at the professional level. A sample of 28 Egyptian male weightlifters (14 elite \& 14 non-elite) and 18 female ( 9 elite \& 9 non-elite) were selected to study the differences between the Egyptian elite and non-elite weightlifters. Also determine of the relationship between MT and the level of achievement was targeted. Participants completed the Mental Toughness Questionnaire (MTQ) evaluating an individual's competitive desire, focus, self-confidence, and resiliency (4 subscales). T-test and Pearson correlation coefficient were used for data analysis. MT of elite was significant than non-elite weightlifters $(\mathrm{p}<0.05,2$-tailed). Subscales associated with MT were also significant at elite. Focus and competitive desire were the most important psychological attributes characterizing the elite male weightlifters, while resilience and focus were at elite female. The correlation between MT and the achievement level was $r=0.974^{* *}(p<0.01,2$-tailed). MT represents a condition for developing the achievement level. It is recommended that sport psychologists should help Egyptian elite weightlifters to develop and refine their MT to enter "high mental toughness range", assisting with the formal integration of psychological training into physical training. As such, this integration may facilitate the effective transfer of mental skills into competition, which can help Egyptian weightlifters to achieve better results in great competitions (e.g., Olympic Games).
\end{abstract}

Key Words: Mental toughness, Achievement level, Weightlifters.

\section{INTRODUCTION}

The sport excellence of super-elite athletes depends on the advantage of using the psychological abilities alongside physical abilities. Gucciardi et al. (22) mentioned the influence of psychological factors on athletic performance have increased significantly nowadays, to such an extent that coaches, athletes, and sport administrators recognize that sport excellence cannot be guaranteed by raw physical talent alone. Psychological abilities help super-elite athletes to mobilize their energy to achieve maximum performance (48). Sport psychologists, coaches and athletes themselves have discovered the benefits of mental development in many sports. In addition, they realize its significance in different situations (sport performance \& competition). Gould et al. (20) reported that $82 \%$ of coaches rated MT as the most important psychological attribute in determining wrestling success. Moreover, a close relationship between mental abilities and sport excellence was recorded $(27,41,45,47,52)$.
MT is having the natural or developed psychological edge that enables athlete to act better than his opponents. Specifically, MT allows athletes to be more tenacious and consistent than the opponents. Also, MT permits them to remain in a case of the challenge, determination, focus, confidence, stability, and in control under pressure $(29,39,40)$. There is evidence that MT involves the use of various psychological skills that enable the best performers to outperform others (12). MT is a concept embedded in a multidimensional framework including personal characteristics, and several conceptual models have been proposed $(3,30)$. MT is important for success in sport due to its cognitive, affective and behavioral components $(3,6,8,12,17,37)$. MT is not a substitute for wellgrounded strokes in athleticism or top physical condition, but when most other things are equal, the mentally tough performer and the team that practices MT will succeed (36). Moreover, MT is important in developing champion athletes (44). MT can transform physically talented athletes into great athletes (22). 
Super-elite coaches and athletes believe that MT may have more to do with winning than do such physical abilities (e.g., speed or power) especially at a high-level competition (58). Sheard (53) pointed out that MT is thought to be a crucial factor for super-elite athletes, since differences in physical and technical abilities are minimal at the professional level. Also, regarding sporting success, wushu (a Chinese martial art) and fencing, medalists players were reported to have more self-confidence and better negative energy control than non-medalists $(32,24)$.

Although this view is endorsed by some researchers, within the Arab Republic of Egypt context, there is still a concerning lack of belief in the importance of psychological factors and their impact on performance. It is consequently not surprising that most weightlifting research (in Egypt) has mainly concentrated on technical and physiological aspects.

Weightlifting sport requires (like other sports) the availability and integration of various components of the athletic achievement (physical, technical, tactical and psychological, etc.). Without this integration, the weightlifter cannot reach the top achievement. However remain many trainers, who focus almost exclusively on the first two components of the athletic achievement mentioned above. Consequently the Egyptian weightlifters still have lack in psychological preparation. Hegazie (26), Rushdi (49) have attributed the low-level of Egyptian weightlifters in recent decades to focus on developing the physical components and a lack of enough knowledge about the psychological factors and its importance. Perhaps one of the most important indicators that confirm this point of view that there was not any Egyptian weightlifter (candidates for Olympic Games), who was able to win an Olympic medal after London Olympic Games 1948 (14,15,25,59). In other words, it was a superiority of competitors/ super-elites (from other countries) in all weight categories.

This means to authors (according to our practical and professional experience in this field) that the development of psychological and mental components is unplanned and not deliberate. This reflected in turn at the lack of the weightlifter ability to control his behavior, the failure to exploit his physical and technical available abilities, the inability to redirect his energies positively, and not to act well with the pressure at hard times during the great competitions. So it had been found that is a need to highlight the importance of MT to Egyptians weightlifters through determining the degree of MT and the differences between elite and non-elite. We are also trying to identify the relationship between MT and the achievement level. The findings of the present study represent importance to make sure that the results in this research area are valid, will enrich the field of weightlifting sport and answer some important applied questions. Moreover, this study will hopefully contribute to an increased interest and positive attitudes towards the importance of psychological factors in weightlifting, which MT is one of.

\section{MATERIAL \& METHOD}

Participants: A total of 46 weightlifters aged between 18 - 26 years (age M. 21,391 $\pm 2,304$ ) participated in the study, including 28 male (14 elite \& 14 non-elite) and 18 female ( 9 elite \& 9 non-elite). The purpose, aims, and potential benefits of the study were explained to trainers for obtaining their approval. Participants were distributed according to the level of achievement and the size of the study population. The major consideration / criteria for these elite weightlifters were that they had won the honor of representing their country in major regional or international events (e.g., Olympic or World or Mediterranean Championship or Arab Tournament). Also they had got at least: one of the top two positions (male \& female) in the final Arab Republic of Egypt Championships (AREC) (Youth, under 20 years old \& First class, greater than 20 years old) for the sports season 2013/2014. While the non-elite weightlifters were selected from those, who have achieved low positions / less than a fifth position (male), less than a fourth position (female) in the AREC 2013/ 2014. Moreover, they did not participate in any competition abroad.

Senior weightlifters were excluded from this study, because the increasing of age might potentially have a negative effect on weightlifters' ability to cope with the physiological demands of competitive sport (5). All participants were still competing.

Procedure: The AREC 2013/ 2014 was chosen for this study, due to its highly competitive nature. The participating weightlifters qualified for the AREC by emerging victorious and by achieving the participation requirements (from the Egyptian Federation of Weightlifting) during Egyptian various regional tournaments of the sports season $2013 / 2014$, thereby giving variance to the sample. 
After reviewing the previous studies, which focused on MT for athletes, The MTQ of Cherry (4) was translated to Arabic language to enable the participants to read it efficiently. MTQ is a fourfactor model; containing the following components: competitive desire, focus, self-confidence, and resiliency. Although there are several other important mental skills and / or some other MTQs in sport, these four components of MT (four-factor model) were chosen to represent the concept of MT of weightlifters in the present study, because: Firstly, this measure / model has been built according to Jones et al.'s (29) definition of MT and this definition was adopted in this study. Secondly, this MTQ includes psychological traits that are believed to be important psychological characteristics of weightlifters in competition (i.e. specificity). Finally, its simplicity (the number of the questionnaire phrases is appropriate that it does not cause boredom for participants during the survey).

In addition, it had been conducted methods related to the quality and standardization of the questionnaire on a sample $(n=16)(8$ elite \& 8 nonelite) of the research population and outside the main sample of the study. The results were as following: the validation by using "Discriminated validation method", significant differences between elite and non-elite weightlifters in MT (T-test = $15.644^{*} ; \mathrm{p}<0.05,2$-tailed); the reliability by using "split-half method", Pearson's correlations also revealed a significant relation between the two halves of MTQ scores ( $r=0.97^{* *} ; \mathrm{p}<0.01$, 2-tailed).

During the AREC 2013/2014 and after the competition of each weight category the target study sample was selected, and then the MTQ has been applied. The 18-item MTQ was administered at a convenient time in a comfortable room setting. Instructions aimed at reducing socially desirable answers (a positive response bias in participant's ratings) were also given (e.g., the weightlifters were not told that the questionnaire was assessing MT only, they were told that it was a measure of "personal styles in competition" basically). Furthermore the participants were instructed to read each statement and circle the answer that best fitted their own view (without interaction with others) and which related with their specific sport "weightlifting".

All the participants provided written informed consent before data collection began (Appendix A). Also they were asked about: if they before joined (during the training or competition) in a psychological program? And all participants answered "NO". They completed the MTQ, which provides a total measure of MT (i.e., the sum of the subscales scores). It also assesses the four components of MT (competitive desire, focus, selfconfidence, and resiliency). A five-point Likert scale was used to allow weightlifters to indicate how much they agreed or disagreed with the items in the MTQ. So that the maximum total score could have been achieved by participant in the 18-item MTQ = 90 degrees $($ more MT), the minimum $=18$ (less MT).

Statistical analysis: All data obtained during the study was treated with stringent confidentiality and anonymity. Data was analyzed using Microsoft Office Excel and the statistical program SPSS (version 17). The participants were divided into different groups (based on their final position on the AREC and the gender). Independent-groups T-test ( $p<0.05$ (2-tailed), was used to compare elite with non-elite. Pearson correlation coefficient at the level 0.01 (2-tailed) was used to determine the relationship between the MT as well as the associated dimensions on one hand and the level of achievement on the other.

\section{RESULTS}

Table 1. Means, standard deviations and T-test of mental toughness scale for comparisons between elite and non-elite (males and females) weightlifters.

\begin{tabular}{|c|c|c|c|c|c|c|c|c|c|c|c|c|}
\hline \multirow{3}{*}{ Mental Toughness } & \multicolumn{6}{|c|}{ Males } & \multicolumn{6}{|c|}{ Females } \\
\hline & \multicolumn{2}{|c|}{ Elite } & \multicolumn{2}{|c|}{ Non-elite } & \multirow{2}{*}{ T-test } & \multirow{2}{*}{$\mathrm{P}$} & \multicolumn{2}{|c|}{ Elite } & \multicolumn{2}{|c|}{ Non-elite } & \multirow{2}{*}{ T-test } & \multirow{2}{*}{$\mathrm{P}$} \\
\hline & $\mathrm{M}$ & $\pm \mathrm{SD}$ & $\mathrm{M}$ & $\pm \mathrm{SD}$ & & & $\mathrm{M}$ & $\pm \mathrm{SD}$ & $\mathrm{M}$ & $\pm \mathrm{SD}$ & & \\
\hline Competitive Desire & 18.86 & 1.17 & 10.86 & 1.70 & $14.50^{*}$ & 0.000 & 17.56 & 0.88 & 9.89 & 2.03 & $10.40^{*}$ & 0.000 \\
\hline Focus & 22.50 & 2.31 & 11.00 & 1.75 & $14.83^{*}$ & 0.000 & 21.56 & 1.33 & 11.11 & 1.54 & $15.40^{*}$ & 0.000 \\
\hline Resiliency & 20.71 & 2.09 & 10.71 & 1.82 & $13.51^{*}$ & 0.000 & 20.89 & 1.45 & 9.67 & 1.58 & $15.68^{*}$ & 0.000 \\
\hline Self-confidence & 17.93 & 1.59 & 10.50 & 1.79 & $11.62^{*}$ & 0.000 & 17.44 & 1.51 & 9.67 & 2.12 & $8.96^{*}$ & 0.000 \\
\hline Total & 80.00 & 5.84 & 43.07 & 4.62 & $18.56^{*}$ & 0.000 & 77.44 & 2.96 & 40.33 & 5.27 & $18.42^{*}$ & 0.000 \\
\hline
\end{tabular}

Difference between Elite and Non-elite weightlifters were significant ${ }^{*} \mathrm{p}<0.05$ (2-tailed) 
Table 2. Correlations between achievement level and mental toughness and its components.

\begin{tabular}{lcccccc}
\hline Variable & & Competitive Desire & Focus & Resiliency & Self-confidence & Total Scale \\
\hline \multirow{2}{*}{ Achievement } & Pearson correlation & $0.945^{*}$ & $0.955^{*}$ & $0.932^{*}$ & $0.945^{*}$ & $0.974^{*}$ \\
& Sig. (2-ailed) & .00 & .00 & .00 & .00 & .00 \\
N & 46 & 46 & 46 & 46 & 46 \\
& & & & &
\end{tabular}

\section{DISCUSSION}

The findings of this study will be discussed in relation to the two objectives and tables outlined above.

1- Determining the degree of mental toughness for Egyptians weightlifters and the differences between elite and non-elite weightlifters, Table (1).

It can be attributed the significant differences ( $p<0.05$, 2-tailed) between elite (male, $\mathrm{M}=80.00 \&$ female, $\mathrm{M}=77.44$ ) and non-elite (male, $\mathrm{M}=43.07$ \& female, $\mathrm{M}=40.33$ ) weightlifters in MT trait in Table (1) results to the previous championships / tournaments experience characterizing elite weightlifters. Connaughton et al. (7) indicated that the development and maintenance of MT associated with many factors (e.g., competitiveness, successes, international competitive experience). Consequently, self-confidence, competitive desire, resiliency and focus are psychological aspects that can be gained through the repeated and continued involvement in competitions (e.g., local / country, Regional, African, Arab, Mediterranean Sea, and World) which are held annually or periodically. It can also be attributed the low degree of total MT for the non-elite (male, $\mathrm{M}=43.07 \&$ female, $\mathrm{M}=40.33$ ) to their limited number of hours per week training as well as the limited number of competitions per year (they do not exceed in most cases three tournaments per year) and the limited participation in local competitions. Gucciardi (21) indicate that the number of hours per week training evidenced significant relationships with "the desire to achieve" and "attentional control" components of MT. Asamoah (2), Lazarus (34), Perry, Williams (46) indicated that accumulative previous tournament experience is a strong indicator of achievement ability, psychological dynamics, and perceived cognitions in a competitive environment. In addition, the familiarity and prior experience within a competitive setting is thought to facilitate coping resources and the perceived possibilities for success (50). This previous explanation in the same line of Jarottova (28) and Katharina (31) who indicated that, there is a positive correlation between MT and climbing / judo experience.

This could be a possible reason, why the Egyptian elite weightlifters (male and female) who had more competition / tournament experience, are on a higher level of MT and performed better than the non-elite weightlifters. Gucciardi et al. (22), Tristan et al. (57) have confirmed that MT is a term that coaches, athletes and sport psychology consultants use when discussing psychological factors that differentiate between successful and less successful athletes.

It was inferred that results from Table (1) meaning the sub-attributes, "Focus" and "Competitive Desire" are the most important psychological characteristics that characterize the elite male weightlifters, while the sub-attributes "resilience" and "Focus" represent the most important psychological characteristics that characterize the elite female weightlifters. In addition, the results indicate that the elite weightlifters have those "four attributes" larger than their non-elite counterparts. Starkes, Ericsson (55) indicated that psychological factors distinguish between successful and less successful athletes.

Results of Table (1) are compatible also with some researches' findings, which acknowledge that MT influences performance / achievement $(22,29)$. Also it differentiates between more and less successful competitors, who are from different competitive levels $(9,23,54)$. This is also across a variety of sports, ranging from golf (56), through rugby, equestrian events, and wrestling $(17,38,47)$, to fencing (24).

Table (1) indicates low averages for non-elite weightlifters in total MT (male, $\mathrm{M}=43.07$ \& female, $M=40.33$ ). It also indicates moderate MT for elite weightlifters (male, $\mathrm{M}=80.00 \&$ female, $\mathrm{M}=77.44$ ), compared to the maximum degree of the MT scale (90 degrees) in the current study. From our point of view, this represents unacceptable and low levels, perhaps this is due to the relative lack of psychological training programs during weightlifters preparation in the national centers and 
sectors in Egypt. These programs can contribute to improve the psychological aspects of the weightlifters and consequently a higher tendency to be able to compete at the Olympics and world competitions.

Furthermore, the results indicates that elite weightlifters should focus on developing their MT through psychological skills training in order to achieve or enter "high MT range"/ "high achievements range such as Olympic games". See also results of Nolte (43). According to Sheard (53) "A hardened, disciplined mindset differentiates between the good and the great, especially at the highest level of competition. Gould et al. (19) found that various performance enhancement skills and characteristics (e.g., MT, confidence and ability to focus) associated with Olympic champions. These results suggest that more support and appropriate development of MT could enhance the weightlifters ability to have made the shift to great.

\section{2- Identify the relationship between mental toughness and the achievement level, Table (2).}

It was observed a positive relationship $(r=$ $0.974^{* *}$ ) between achievement level and MT in the results of Table (2). Schnabel et al. (51) show that each achievement is influenced by psychological factors and this in turn can have an impact on other important achievement factors. Additionally, the strongest correlation was found between the level of achievement and the sub-attribute „Focus". This emphasizes the importance of the development of MT for weightlifters in general, and "focus" particularly. Focus is one of the most important psychological characteristics, which characterizes the higher level weightlifters $(1,13,35)$. The ability to block out distractions and to remain focused on the "weight lifting process" has been associated with success in competition. More focused weightlifters have the ability to mobilize higher muscular strength to lift heavy weights at the critical moment (1). This means that "MT is not only relevant in the face of adversity but also facilitates an appropriate focus and motivation even when circumstances are favorable" (22). It was also inferred from results that self-confidence and competitive desire represent important factors in weightlifting, without them it would be impossible to lift maximum weights during the major competition. Moreover, it was appeared from results that without a strong desire to compete, it would also be hard for a weightlifter to be the best.
In addition to this, we believe that it will be difficult to excel at the important competitions in case of non-availability of resilience. Often unforeseen circumstances occur during the weightlifting competition (e.g., "the planning mistakes"; changing the weight quickly and the lack of enough time to warm up, and the failure in two attempts from three, etc.). This requires that the weightlifter has enough resilience (the ability to withstand, endure negative outcomes, recover, remain positive, grow in the face of stressors and changing demands and go on to experience success) to act efficiently within the situation. Ajan, Baroga (1) indicated that affective stability is considered one of the most psychological traits that characterize super-elite weightlifters. Crust (11) proved that MT and affect intensity were found to be unrelated.

The previous results indicated that the MT represents a condition for developing the achievement level. This results are compatible with some research findings, which adopted that MT contributes to produce successful performance $(1,3,10,12$, $16,17,18,19,22,24,27,28,31,32,33,39,40,42$, $43,45,47)$, and some of them indicated that total MT scales and sub-scales were positively correlated with the achievement level; the more MT (as well its components), the higher achievement level will be.

In conclusion; there is a need to create sufficient opportunities to participate in competitions for weightlifters (Experience is one of the factors developing and stabilizing of mental skills). The psychological preparations for weightlifters (psychological intervention programs can be structured to develop the MT of weightlifters systematically) must be taken into serious consideration in order to raise their achievement potential. The knowledge obtained from this study can contribute towards strengthening an awareness of the importance of psychological trainings and their application at all levels of weightlifter's preparations. Thus, we should conduct more comparative research between our weightlifters and their counterparts in developed countries. Further investigation is needed and future research should use experimental designs to examine the differences and relationships in more detail.

\section{REFERENCES}

1. Ajan T, Baroga L. Weightlifting fitness for all sports. I.W.F, Medicina Pub. House, Budapest, 1988. 
2. Asamoah B. The role of mental toughness, psychological skills and team cohesion in soccer performance. Master thesis, Stellenbosch University, Faculty of Education, 2013.

3. Bull SJ, Shambrook CJ, James W, Brooks JE. Towards an understanding of mental toughness in elite English cricketers. Journal of Applied Sport Psychology, 2005; 17(3): 209-227.

4. Cherry HL. Psychometric analysis of an inventory assessing mental toughness. Master Thesis, University of Tennessee Knoxville, 2005.

5. Castagna C, Abt G, D'ottavios S, Weston M. Age-related effects on fitness performance in elite level soccer referees. Journal of Strength and Conditioning Research, 2005; 19: 785790.

6. Clough PJ, Earle K, Sewell D. Mental toughness: The concept and its measurement. In I. Cocerill (Ed.), solutions in sport psychology, London: Thomson, 2002: 32-43.

7. Connaughton D, Hanton S, Jones G. The development and maintenance of mental toughness in the world's best performers. The Sport Psychologist, 2010; 24: 168-193.

8. Connaughton D, Hanton S, Jones G, Wadey R. Mental toughness research: Key issues in this area. International Journal of Sport Psychology, 2008; 39(3): 192-204.

9. Crust L. Mental toughness in sport: A review. International Journal of Sport and Exercise Psychology, 2007; 5: 270-290.

10. Crust L. A review Implications for future researchers. Personality and Individual Differences, 2008; 45(7): 576-583.

11. Crust L. The relationship between mental toughness and affect intensity. Personality and Individual Differences, 2009; 47(8): 959-963.

12. Crust L, Clough PJ. Relationship between mental toughness and physical endurance. Perceptual and Motor Skills, 2005; 100: 192-194.

13. Elemiri A. The Effect of a suggested program for improving some kinesthetic percepts on the achievement level for beginners in weightlifting sport. Doctoral Thesis, Almansoura University, Faculty of sports Education, Egypt, 2010.

14. Elemiri A, Hassan M. Beginners training in weightlifting. Almanar Press, Almansoura, Egypt, 2011: 3-15.

15. Ezzat E. A future vision for schools of talented athletes. National Conference for talented 9-10 April "talent locomotive progress", Cairo, 2000; 161-170.

16. Fourie $S$, Potgieter JR. The nature of mental toughness in sport. South African Journal for Research in Sport, Physical Education and Recreation, 2001; 23: 63-72.

17. Golby J, Sheard M. Mental toughness and hardiness at different levels of rugby league. Personality and Individual Differences, 2004; 37: 933-942.

18. Golby J, Sheard M, Lavallee D. A cognitive-behavioural analysis of mental toughness in national rugby league teams. Perceptual and Motor Skills, 2003; 96: 455-462.

19. Gould D, Dieffenbach K, Moffett A. Psychological talent and their development in Olympic champions. Journal of Applied Sport Psychology, 2002; 14: 172-204.
20. Gould D, Hodge K, Peterson K, Petlichkoff L. Psychological foundations of coaching: similarities and differences among intercollegiate wrestling coaches. The Sport Psychologist, 1987; 1: 293-308.

21. Gucciardi DF. The relationship between developmental experiences and mental toughness in adolescent cricketers. Journal of Sport Exercise Psychology, 2011; 33(3): 370-393.

22. Gucciardi DF, Gordon S, Dimmock JA. Towards an understanding of mental toughness in Australian football. Journal of Applied Sport Psychology, 2008; 20: 261-281.

23. Gucciardi DF, Gordon S, Dimmock JA. Evaluation of a mental toughness training program for youth-aged Australian footballers: II. A qualitative analysis. Journal of Applied Sport Psychology, 2009; 21: 324-339.

24. Hagag H, Ali M. The relationship between mental toughness and results of the Egyptian fencing team at the 9th all-Africa games. Ovidius University Annals, Romania, Series Physical Education and Sport Science, Movement and Health, 2014; 14 (1): 85-90.

25. Hanna G. The history of weightlifting in Egypt and the world. MG Mark Press, Cairo, Egypt, 2011; 82-202.

26. Hegazie M. Effects of developing motor imagery on two hand clean and jerk lift in weightlifting sport. Dissertation, Alexandria University, Faculty of Physical Education, Egypt, $1993 ; 3-4$

27. Ismaiel $M$, Abdelrahman U. Mental toughness and its relationship with the performance strategies of the fencing players in the national team of Egypt. Journal of Science and Arts sport, Faculty of Physical Education of the Girls at Helwan University, 2007; Vol. December; 307-336.

28. Jarottova E. Psychometrische Analyse, Dimensionalität und Leistungskorrelate von Mental Toughness im Klettersport. Diplomarbeit, Wien Universität, 2013.

29. Jones G, Hanton S, Connaughton D. What is this thing called mental toughness? An investigation of elite sport performers. Journal of Applied Sport Psychology, 2002; 14(3), 205-218.

30. Jones G, Hanton S, Connaughton D. A framework of mental toughness in the world's best performers. The Sport Psychologist, 2007; 21(2), 243-264.

31. Katharina AH. Psychometric analysis and dimensionality of mental toughness in the context of judo performance. Thesis, Wien University, 2012.

32. Kuan G, Roy J. Goal profiles, mental toughness and its influence on performance outcomes among Wushu athletes. Journal of Sports Science and Medicine, 2007; 6: 28-33.

33. Kudlackova K. The Relationship between mental toughness, relaxation activities, and sleep in athletes at different skill levels. Electronic theses, The Florida State University, 2011.

34. Lazarus RS. How emotions influence performance in competitive sports. The Sport Psychologist, 2000; 14: 229-252.

35. Lippmann J, Kohl M. Gewichtheben : Rahmentrainingskonzeption für Kinder und Jugendliche im Leistungssport. Landessportbundes NW \& BVDG, 1993.

36. Loehr JE. The new mental toughness training for sports. New York, NY: Plume, 1995: 127. 
37. Meggs J, Ditzfeld C, Golby J. Self-concept organisation and mental toughness In sport. Journal of Sports Sciences, 2014; 32(2): 101-109.

38. Meyers MC, Bourgeois AE, Leunes A, Murray NG. Mood and psychological skills of elite and sub-elite equestrian athletes. Journal of Sport Behavior, 1999; 22(3): 399-409.

39. Middleton SC, Marsh WH, Martin JA, Richards EG, Perry C. Discovering mental toughness: A qualitative study of mental toughness in elite athletes. SELF Research Centre, University of Western Sydney, Australia, 2004.

40. Middleton SC, Marsh WH, Martin JA, Richards EG, Savis J, Perry C, Brown R. Mental toughness: Is the mental toughness test tough enough? Self-concept Enhancement and Learning Facilitation Research Centre, University of Western Sydney, Australia, 2003.

41. Newland A, Newton M, Finch L, Harbke C, Prodlog L. Moderating variables in the relationship between mental toughness and performance in basketball. Journal of Sport and Health Sciences, 2013; 2(3): 184-192.

42. Nicholls AR, Polman RJ, Levy AR, Backhouse SH. Mental toughness in sport: Achievement level, gender, age, experience, and sport type differences. Personality and Individual Differences, 2009; 47(1): 73-75.

43. Nolte PL. The effect of variable environment factors on sport performance. Master Thesis, University of Johannesburg, 2013.

44. Norris EK. Epistemologies of champions: A discursive analysis of champions' retrospective attributions; looking back and looking within. Michigan: Michigan University, Microfilms International, 1999.

45. Pasha A. The mental toughness and its relationship to sports achievement and its impact on players of high levels sports. Master Thesis, Tanta University, Faculty of Physical Education, 2011.

46. Perry JD, Williams JM. Relationship of intensity and direction of competitive trait anxiety to skill level and gender in tennis. The Sport Psychologist, 1998; 12: 169-179.

47. Rana SM. Assessment of mental toughness among high and low achievers Indian wrestlers: A comparative study.
Research Journal of Physical Education \& Sports Sciences, 2009; 4: 60-70.

48. Ratib U. Psychological skills training - applications in sports field. Alfekr Alarabie Press, Cairo, Egypt, 2004.

49. Rushdi S. Mental training program for correct wrongtrajectory of the bar for Weightlifters in the two snatch lift. Doctoral Thesis, Helwaan University, Faculty of Physical Education, Egypt, 1999.

50. Salvador A. Coping with competitive situations in humans. Neuroscience and Behavioral Reviews, 2005; 29: 195-205.

51. Schnabel G, Harre D, Krug J, Borde A. Training swissenschaft. Berlin: Sportverlag, 2003.

52. Sheard M. A Cross-national analysis of mental toughness and hardiness in elite university rugby league teams. Perceptual and Motor Skills, 2009; 109: 213-223.

53. Sheard M. Mental toughness: The mindset behind sporting achievement. London: Routledge, 2010.

54. Sheard M, Golby J, Van Wersch A. Progress towards construct validation of the Sports Mental Toughness Questionnaire (SMTQ). European Journal of Psychological Assessment, 2009; 25(3): 186-193.

55. Starkes JL, Ericsson KA. Expert performance in sports: Advances in research on sport expertise. Champaign, IL: Human Kinetics, 2003.

56. Thomas PR, Over R. Psychological and psychomotor skills associated with performance in golf. The Sport Psychologist, 1994; 8(1): 73-86.

57. Tristan JC, Clifford JM, Gucciardi DF. Understanding of mental toughness in Australian soccer: Perceptions of players, parents and coaches. Journal of Sports Sciences, 2010; 28: 699-716.

58. Williams JM. Applied sport psychology: Personal growth to peak performance. New York, NY: McGraw-Hill Higher Education, 2009.

59. http://www.iwf.net/results/results-byevents/?event_type=Olympic+Games\&event_age=all\&event_ nation $=$ all $\& x=13 \& y=8,2014$. 